\title{
A new species of the genus Opalimosina Roháček (Diptera, Sphaeroceridae) from the Oriental and Australasian Regions
}

\author{
Toshihiko HaYASHI \\ Department of Medical Entomology, National Institute of Infectious Diseases, \\ Toyama 1-23-1, Shinjuku-ku, Tokyo 162-8640, Japan
}

(Received: 16 April 2009; Accepted: 7 May 2009)

\begin{abstract}
The Opalimosina specimens from the Australasian Region are studied. A new species, Opalimosina (O.) australis sp. nov. from Fiji, Papua New Guinea and Indonesia (Papua Barat), is described as new to science. The record of Opalimosina $(O$.) calcarifera (Roháček, 1975) from Pakistan (Hayashi, 1989) was a misidentification, and it was the same species as a new species described in this paper, so the specimens examined by Hayashi (1989) are included in the type series. Therefore, the record of $O$. calcarifera is to be eliminated from Pakistan.
\end{abstract}

Key words: Opalimosina, Sphaeroceridae, Diptera, Australasian Region, Pakistan, a new species

According to Roháček et al. (2001), nine species of the genus Opalimosina Roháček are known mainly from the Palaearctic and Oriental Regions. In the Australasian Region, only one species, Opalimosina (O.) mirabilis (Collin, 1902) was known from Australia and New Zealand (Harrison, 1959; Richards, 1973), which is nearly a cosmopolitan species possibly owing to human activities.

I studied the Opalimosina specimens from the Australasian Region, and found one new species, which is closely related to Opalimosina (O.) calcarifera (Roháček, 1975).

I recorded O. calcarifera from Pakistan (Hayashi, 1989), but after I re-examined the specimens, I determined there had been a misidentification. It was conspecific with the new species described in this paper, so, the record of $O$. calcarifera should be eliminated from Pakistan.

The type specimens are deposited in the collection of the Department of Medical Entomology, The National Institute of Infectious Diseases, Tokyo (NIID), and Zoological Division, Museum Zoologicum Bogoriense, Indonesian Institute of Sciences, Bogor (LIPI).

\section{Opalimosina (Opalimosina) australis Hayashi, sp. nov.} (Figs. 1-9)

Opalimosina (O.) calcarifera (Roháček, 1975).--Hayashi, 1989: 64.

Body length $0.9-1.3 \mathrm{~mm}$ (holotype $1.0 \mathrm{~mm}$ ), general color brown to dark brown.

Head: Generally dark brown, anterior part of frons and gena brownish; 4-5 if, foremost one a little shorter; eye oval, its longest diameter about 3 times as long as smallest genal width; antenna dark brown; arista about 5 times as long as first flagellomere, moderately long pubescent.

Thorax: Dark brown, brown microtomentose; $2 d c$, anterior one only slightly longer than microsetae; about 6 rows of irregular ac microsetae in front of suture; upper part of 


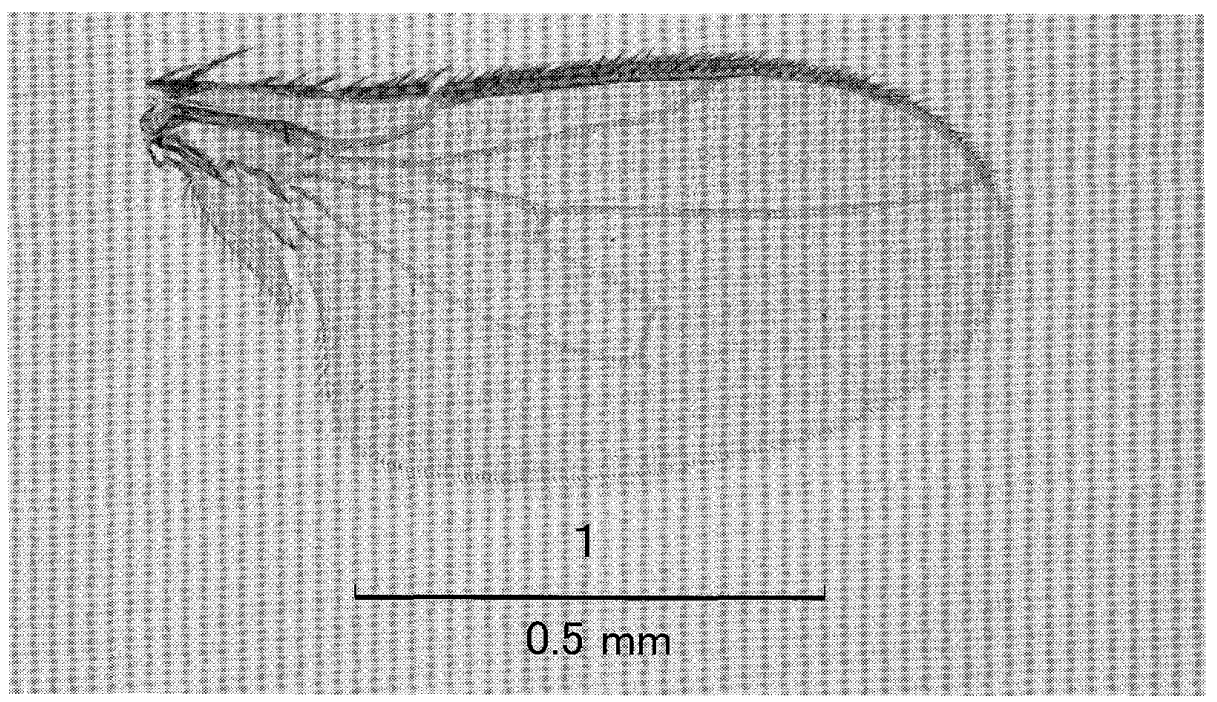

Fig. 1. Wing.-Opalimosina australis sp. nov. (male paratype).

katepisternum yellowish along suture, 2 kepst, anterior minute; scutellum rounded triangular, 2 sctl, apical sctl about 1.5 times as long as lateral sctl.

Wing (Fig. 1): Almost hyaline, veins pale yellow; Costa brown, just ending at the end of $\mathrm{R}_{4+5}$; second costal sector almost as long as or a little longer than third; $\mathrm{R}_{4+5}$ gently curved forwards; $\mathrm{r}-\mathrm{m}-\mathrm{dm}-\mathrm{cu}: \mathrm{dm}-\mathrm{cu}=$ about 2.3 ; halter with dark brown knob and pale brown stem.

Legs: Mostly brown to dark brown; mid tibial chaetotaxy as in Fig. 2, ventrally with $a v$ seta on basal $1 / 2$ and strong apical seta; hind tibial spur (Fig. 3) small.

Abdomen: Dark brown, brown microtomentose. Male. Sternite 5 (Fig. 4) posteromedially distinctly incised and with a pair of characteristic structures each side of this incision, central part with large pale area; epandrium (Fig. 5) with short and sparse setae, cercus long; surstylus (Fig. 5) closely resembling that of O. calcarifera, but lacking strong setae on posteroventral corner; inner genitalia as in Fig. 6, apical part of paramere somewhat pointed, epiphallus large and long, apically prolonged sharply, distiphallus rather simple. Female. Postabdomen as in Figs. 7 and 8, tergite 8 with dark pigmented thumb-like projections laterally; tergite 9 very narrow and completely fused with cerci; cercus without strong spine; spermathecae as in Fig. 9.

Type series. Holotype: ð, Sigatoka, Viti Levu Is., FIJI, 17-19 Dec. 1994, T. Hayashi (NIID). Paratypes. FIJI: $100^{7}, 9$ 우, same data as holotype (NIID). PAPUA NEW GUINEA: 207, Regina Creek, Wau, 25 Dec. 1981, S. Shinonaga (NIID); 10, Mt. Kaindi, 2,000 m, Morobe Dist., 18 July 1982, S. Shinonaga (NIID); 207 , 1우, ditto, 1,600 m, 19 April 1995, H. Kurahashi (NIID); 10 , Baiyer River, Mt. Hagen, 1,200 m, 4-8 Aug. 1982, S. Shinonaga (NIID). INDONESIA: 1 $\sigma^{7}$, Arabia, Waigeo Is., Papua Barat, 3-5 June 2007, human dung trap (LIPI). PAKISTAN: 20, Balakot, NWFP, 2 Aug. 1988, T. Hayashi (NIID).

Etymology. The new species refers to its southern distribution.

Distribution. Fiji (Viti Levu Is.), Papua New Guinea, Indonesia (Waigeo Is., Papua Barat) and Pakistan.

Remarks. Hayashi (1989) recorded O. calcarifera (Roháček, 1975) from Pakistan. I re-examined the specimens, and they were all conspecific with this species. Therefore, the records of $O$. calcarifera should be eliminated from Pakistan.

This species is closely related to $O$. calcarifera, and the most characteristic feature is the shape of paramere (Fig. 6). Other differences are as follows: Ventral setae of surstylus almost same strength, not existing strong setae on hind corner of surstylus; epiphallus 

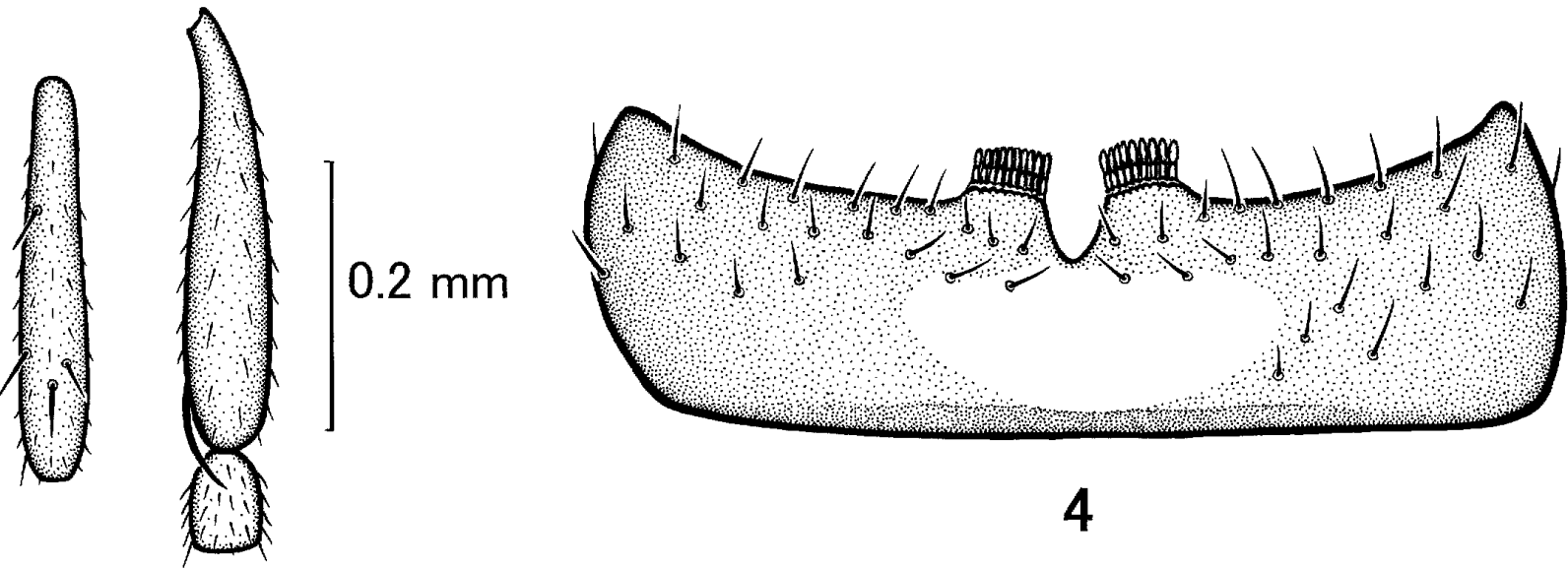

4

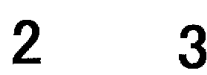

$0.2 \mathrm{~mm}$
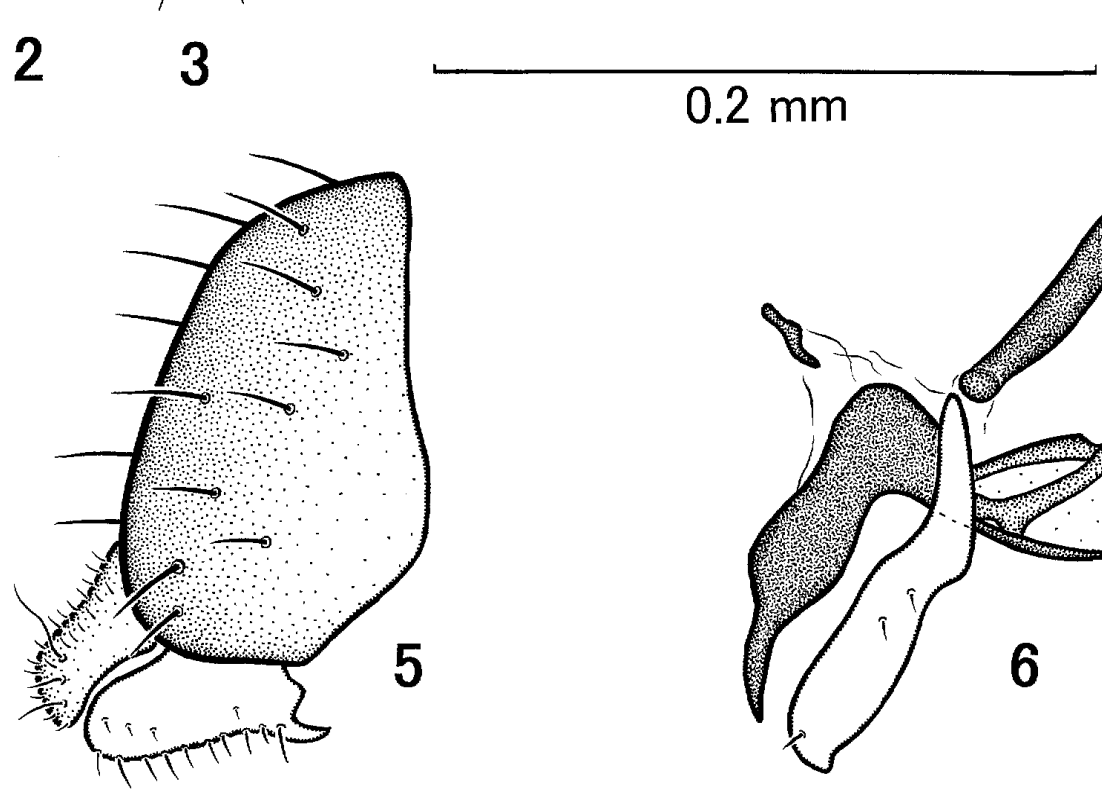

5

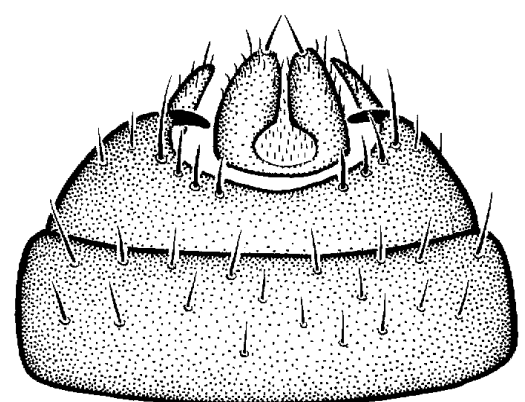

7
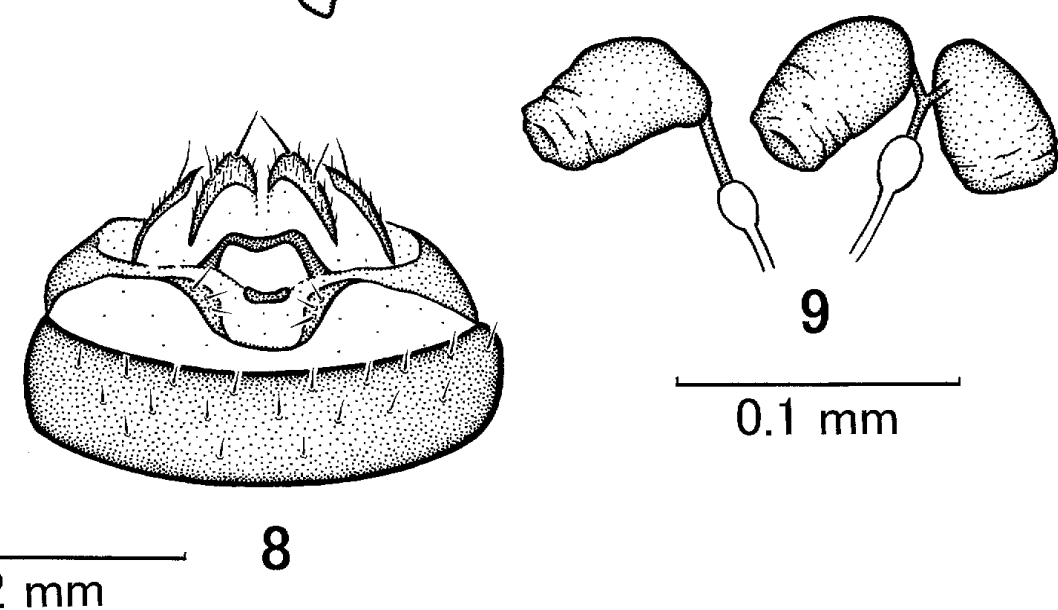

9

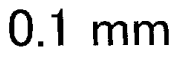

Fig. 2-9. Opalimosina australis sp. nov. - 2, left mid tibia, dorsal view; 3 , male hind tibia, anterior view; 4, male sternite 5; 5 , male terminalia, lateral view; 6 , male inner genitalia; 7 , female terminalia, dorsal view; 8 , ditto, ventral view; 9 , spermathecae.

more sharply prolonged; female abdominal tergite 8 with dark pigmented thumb-like projections laterally. 


\section{ACKNOWLEDGEMENTS}

I express my sincere thanks to Drs. H. Kurahashi of National Institute of Infectious Diseases, and S. Shinonaga of Tokyo Medical and Dental University for giving me with material from Papua New Guinea. I also thank Dr. S. Hartini (LIPI) for giving me the opportunity to examine the sphaerocerid specimens preserved in Museum Zoologicum Bogoriense. This study was partly supported by the Grant-in-Aid for Monbusho International Scientific Research Program (Field Research) to the Toyama Medical and Pharmaceutical University in 1988 (Grant No. 63041058) and the Grant-in-Aid from the Japan Society for the Promotion of Science (No. 17405011).

\section{REFERENCES}

Harrison, R. A. 1959. Acalyptrate Diptera of New Zealand. Bull. N. Z. Dept. Sci. Ind. Res., 128: 1-382.

Hayashi, T. 1989. The genus Opalimosina (s. str.) Roháček, 1983 from Pakistan (Diptera, Sphaeroceridae). Jpn. J. Sanit. Zool., 40 (suppl.): 61-64.

Richards. O. W. 1973. The Sphaeroceridae (=Borboridae or Cypselidae; Diptera Cyclorrhapha) of the Australian Region. Aust. J. Zool. Suppl. Ser., 22: 297-401.

Roháček, J., Marshall, S. A., Norrbom, A. L., Buck, M., Quiros, D. I. and Smith, I. 2001. World catalog of Sphaeroceridae (Diptera). 414 pp. Slezské zemské museum, Opava. 